\title{
Explaining suicide: Identifying common themes and diverse perspectives in an urban Mumbai slum
}

\section{Citation}

Parkar, Shubhangi R., Balkrishna B. Nagarsekar, and Mitchell G. Weiss. 2012. "Explaining Suicide: Identifying Common Themes and Diverse Perspectives in an Urban Mumbai Slum." In Social Science \& Medicine 75, no. 11: 2037-2046. doi:10.1016/j.socscimed.2012.07.002.

\section{Published Version}

doi:10.1016/j.socscimed.2012.07.002

\section{Permanent link}

http://nrs.harvard.edu/urn-3:HUL.InstRepos:35642509

\section{Terms of Use}

This article was downloaded from Harvard University's DASH repository, and is made available under the terms and conditions applicable to Other Posted Material, as set forth at http:// nrs.harvard.edu/urn-3:HUL.InstRepos:dash.current.terms-of-use\#LAA

\section{Share Your Story}

The Harvard community has made this article openly available.

Please share how this access benefits you. Submit a story.

\section{Accessibility}


Title: Explaining suicide: Identifying common themes and diverse perspectives in an urban Mumbai slum 


\section{Explaining suicide: Identifying common themes and diverse perspectives in an urban Mumbai slum}

\section{Abstract}

Rates, demographics and diagnostics, which are the focus of many studies of suicide, may provide an insufficient account without adequate consideration of psychological, social and cultural contexts and motives. Furthermore, reported explanations of suicide are shaped not only by events but also the relationship of survivor respondents explaining the suicide. An explanatory model interview for sociocultural autopsy has been used to assess underlying problems and perceived causes. This study in a low-income community of Mumbai in 20032004 compared accounts of the closest family survivors and more distant relationships. Our study design distinguished series-level agreement (i.e., consistency of accounts within a group) and case-level agreement for particular cases. Serious mental illness was the perceived cause reported by a respondent in either group for $22.0 \%$ of index suicides, but case-level agreement was only 6.0\%. Regarding financial stressors, more closely related family respondents focused on acute stressors instead of enduring effects of poverty. Caselevel agreement was high for marital problems, but low for other sources of family conflict. Tension was a feature of suicide reported in both groups, but case-level agreement on tension as a perceived cause was low $($ kappa $=.14)$. The role of alcohol as a perceived cause of suicide had high series level agreement (46.0\% in both groups) and case-level agreement $(\mathrm{kappa}=.60)$, suggesting comparable community and professional views of its significance. The study shows that it is relevant and feasible to consider general community patterns and particular survivor interests. Findings from this study recommend an approach to sociocultural autopsy to assess reasons for suicide in community studies. Findings clarify diverse views of underlying problems motivating suicide that should be considered to make mental health care more effective in assessing risk and preventing suicide. 


\section{Keywords:}

India; psychological autopsy; sociocultural autopsy; survivor accounts; urban mental health; cultural epidemiology 


\section{Background}

It is important to understand the reasons for suicide, so that efforts to prevent it are well-grounded and guided by locally relevant motivations, and so that an appreciation of community-reported reasons for suicide may contribute to the broader interests of mental health in services and community action. Although rarely considered, It is also important to recognize that explanations of suicide are likely to be influenced by the perspective of whoever is explaining it, and preferred explanations may reflect professional values, personal relationships to the deceased, and the level of available details concerning a behaviour with complex determinants (Jacob, 2008; Phillips, 2004). Mental health professionals concerned with suicide prevention typically focus on the role of high-risk psychiatric disorders (Goldsmith, Pellmar, Kleinman \& Bunney, 2002; Harris \& Barraclough, 1997), because their training and professional priorities suggest effectiveness relies on identification and treatment of mental illness that puts people at risk for suicide. This orientation guides strategies for universal and selective prevention targeting high-risk groups (Bertolote, Fleischmann, De Leo \& Wasserman, 2004).

Recent work suggests the relevance of considering the implications of other ways of explaining suicide, complementing the analysis of high-risk psychiatric disorders with consideration of local accounts of suicide from survivor informants (Parkar, Nagarsekar \& Weiss, 2009; Phillips, Yang, Zhang, Wang, Ji \& Zhou, 2002) and patients' accounts of deliberate self-harm (Parkar, Dawani \& Weiss, 2006; Parkar, Dawani \& Weiss, 2008). Reasons for suicide reported by family, friends, and the popular press typically focus on the triggers and underlying problems, which may be regarded as perceived causes of suicidal behaviour. Newspaper accounts may refer to financial disaster, disturbed relationships, marital problems, and a variety of other issues and conflicts. Community studies of suicide in Kaniyambadi Block, Vellore District, in Tamil Nadu, highlight the underappreciated role of ongoing stress and chronic pain as reasons for suicide, in contrast with overestimation of the role of psychiatric disorders based on uncritical use of symptom check lists that are too easy to apply (Manoranjitham, Rajkumar, Thangadurai, Prasad, Jayakaran \& Jacob, 2010). 
Furthermore, attention to social determinants, such as economic problems leading to farmer suicides, suggest an alternative to the primary role of psychopathology (Sainath, 2010).

Traditional Hindu concepts of death in India typically regard suicide as a bad death. Although it does not necessarily stigmatize the family, cremation may be disallowed. The tradition is concerned with reasons for suicide, inasmuch as some reasons, such as inability to attend to required rituals at the end of life, may make suicide permissible (Parry, 1994).

Research in the rural Sundarban region of West Bengal considered community explanations of suicidal behaviour (Chowdhury, Shashmal, Dutta \& Weiss, 2004).

Vijayakumar and colleagues (Vijayakumar, John, Pirkis \& Whiteford, 2005) emphasized the role not only of high-risk psychiatric disorders but also the importance of considering local contextual factors to guide prevention. Research on urban mental health in a Mumbai slum highlights the impact of contextual features of harsh social settings contributing to mental health problems (Parkar, Fernandes \& Weiss, 2003).

Although mental health professionals are sensitive to the relatively more personal social contexts of a psychiatric history, broader social contexts are also relevant. These include gender, livelihood opportunities, environmental stressors (e.g., air, water and soil pollution), infrastructure and sanitation, and crowding in a slum community. The interrelationship of these various psychosocial and ecosocial factors is central to the agenda for needed developments in social epidemiology (Krieger, 2001). Our approach, based on an explanatory model framework, identifies local perceived causes, underlying problems and triggers for suicide, distinguishing relatively more enduring motivations and immediate precipitating factors. An emphasis on social and cultural determinants complements the conventional approach to psychological autopsy, which may be regarded as comparable to the aims of verbal autopsies. Although verbal autopsies and psychological autopsies acknowledge the importance of social contexts, their priority and validity is based on ascertaining a medical or psychiatric diagnosis. Verbal autopsies are typically used for assessing the medical cause of death in health demographic surveillance (Gajalakshmi \& Peto, 2006) and psychological autopsies are typically used to identify psychiatric causes of 
suicide (Appleby, Dennehy, Thomas, Faragher \& Lewis, 1999; Beautrais, 2001; Cavanagh, Owens \& Johnstone, 1999). Our approach to sociocultural autopsy augments this approach with more attention to social and cultural determinants.

A previous report of experience using a sociocultural autopsy explained the need and value of enhancing psychological autopsies (Parkar et al., 2009). Its development is consistent with the interest of more recent reviews, which acknowledge the need for improving the next generation of psychological autopsies, both the content of interviews for which consideration of sociocultural content is relevant (Conner, Beautrais, Brent, Conwell, Phillips \& Schneider, 2011) and procedures for assessment (Conner, Beautrais, Brent, Conwell, Phillips \& Schneider, 2012), for which consideration of how accounts from multiple respondents relate to one another is relevant. These reviews of Conner highlight the challenge of integrating reports of multiple respondents in the next generation of psychological autopsy studies.

In the course of our previous research on sociocultural autopsies, which was based on interviews with the closest surviving relative (Parkar et al., 2009), interactions with other family suggested that different relatives had different ideas about the suicide. It appeared that all survivor accounts of a single suicide were not the same. This led to development of a substudy, reported here, based on interviews with another relative in a second series of respondents to examine the common and distinctive features of survivor accounts of index cases of suicide.

This study aimed to address relevant but unexamined questions about the role of personal relationships and perspectives, and how they influence explanations of suicide among survivors. It examined patterns of distress, perceived causes of the suicide, and awareness of prior help seeking, as reported by different survivors in independent assessments. Using quantitative and qualitative methods to study the variety, distribution and priority issues from narrative accounts of survivors, we aimed to extend the scope of previous research on reasons for suicide by considering consistency and diversity in survivor accounts, and their implications. 


\section{Methods}

Our approach is rooted in the framework of cultural epidemiology, which has been described by Trostle (Trostle, 2008) as "a set of methods and theoretical rationales for linking culture to human health at the population scale." We consider the theoretical basis of cultural patterning of distress and its meaning in a cultural epidemiology (Trostle, 2005), which complements the better known disciplinary framework of social epidemiology. Our approach emphasizes cultural concepts of meaning and motivation, in addition to the influence of social variables.

\section{Setting}

The study was initiated in February 2003 and completed in the first half of 2004 in Malavani, a slum community of Malad, which is a suburb $35 \mathrm{~km}$ north of central Mumbai. The total population of Malavani was approximately 150,000, with $60.1 \%$ Muslims, $38.2 \%$ Hindus and $1.7 \%$ Christians, according to the census of 2001. Residents included migrants seeking work in Mumbai from all parts of India, as well as refugees from Bangladesh. Socioeconomic features and environmental conditions of the community are compelling. Although the quality of housing and infrastructure may vary considerably, for the most part they are inadequate, unhygienic and a source of stress. While many ecosocial limitations in the community infrastructure are common for all slum dwellers, some living in unsanctioned slums are also subject to the threat of demolition of their rough (kaccha) housing. Unemployment, alcoholism, domestic violence, and other characteristic social problems of slum communities are formidable. The impact of these conditions on mental health in the Malavani slum has been elaborated in another report (Parkar et al., 2003). According to local police records for 2003, the suicide rate in Malavani was 12.0 per 100,000 , with a male:female ratio of 1:1.45, suggesting a need to explain the high proportion of women.

\section{Instrument}

An explanatory model interview based on the EMIC framework of cultural epidemiology was developed as a tool for sociocultural autopsy. This methodological 
approach was originally developed for clinical study of patients; it enabled integrated quantitative and qualitative study of the features of illness-related experience (local categories and patterns of distress), meaning (perceived causes of illness) and help-seeking behaviour from the vantage point of patients (Weiss, 1997; Weiss, 2001). It was adapted for study of survivor's ideas about problems of an index suicide case, rather than an account of problems by that person prior to suicide. It therefore assessed respondents' ideas of the underlying problems of the index suicide, based on open-ended questions about the problems leading to the suicide and more specific follow-up questions. A focus on perceived causes followed questions about broad consideration of underlying problems. Although there is some overlap in the two lines of inquiry, together they enabled the respondent to elaborate relevant contexts, enduring stressors and precipitating factors. The interview also considered previous help seeking known to the respondent for problems associated with the suicide.

\section{Design}

Fifty persons who had died from suicide during the period from 1997 to 2003 were identified from police records and traced in the community with the help of community health workers. The closest surviving first-degree relative of the deceased who could provide an account of the life history and circumstances of the index suicide was identified and asked to participate in the study. These initial interviews were designated as the A series. A secondseries of interviews was conducted with another survivor informant for each of the 50 index suicide cases, and designated as the B series of respondents.

All interviews were administered by a research psychiatrist who participated in the development of the EMIC interview for sociocultural autopsy, and who was trained to use it. He began each interview by explaining the aims and interests of the study in social contexts of suicide and the nature of questions in the interview. Responses to questions about the underlying problems that respondents identified with the suicide were coded, and narrative accounts of features of the suicide were linked to questions of the interview and included in the interview data set. 
The study was reviewed and approved by the KEM Hospital Ethics Committee.

Analysis

Analysis of topics covered in the interview considered the categories of response coded from the two interviews for each index suicide and qualitative analysis of each narrative prose account. Categorical and numeric data for quantitative analysis were entered in an Epi Info entry program with logic and range checks, and these data were imported into SAS version 9.1 for statistical analysis. We examined the frequency of categorical responses for categories of distress reflecting the context of underlying problems, perceived causes, types of identified help seeking, and other features of the suicide. Variables for these coded responses from the series $A$ and series $B$ interviews were compared, and agreement of $A$ group and B-group respondents was assessed with reference to coded categories.

The comparison considered both series-level and case-level agreement. Series-level agreement refers to whether the category was reported at a similar rate in both groups of respondents, regardless of whether respondents agreed on particular cases. We considered case-level agreement, based on whether the respondents agreed on categories in their accounts of a particular index suicide. A situation in which $50 \%$ of the respondents identify a particular category of comparison, but with total disagreement on the category for all cases, illustrates the extreme of very high series-level agreement in the absence of any case-level agreement. At high rates of agreement, case-level agreement is more likely to occur by chance, and the Kappa statistic was used to correct for chance agreement (Ludbrook, 2002). The McNemar statistical test of agreement was used to assess series-level agreement, and the analysis marked such categories with p-values less than $0.20,0.10$ and 0.05 to indicate suggestive and significant series-level discrepancies.

Comparison data were presented in tables with columns indicating the percentages of the index suicide for which a category was identified by either respondent, by both respondents, and by the series-A and Series-B respondents. The agreement fraction 
indicates the percentage of index suicides presented by either respondent that were identified by both respondents.

Qualitative data were managed and analysed with a computer-assisted qualitative data analysis software program, MAXQDA version 7. First-level deductive coding based on the framework of the EMIC interview was completed using the formatting and automatic coding feature of the software. Second-level inductive coding was done manually (Lewins \& Silver, 2007). Comparison variables of the Epi Info data set were imported into MAXQDA. These selection variables were used to activate relevant subgroups of respondents for qualitative analysis of thematically coded narratives, which clarify features of series-specific and case-level disagreement for comparison variables.

\section{Results}

Sample characteristics of the index suicides are summarized in table 1. Sample characteristics of the series A and B respondents are summarized in table 2 . As in the community at large, the index suicides were notable for low-income and minimal education: $62.0 \%$ had no more than primary education, and $40.0 \%$ had none at all. Most were married (64.0\%) and a little more than half were women (56.0\%). Although the majority population of the community is Muslim, they comprised only $22.0 \%$ of the identified index suicides.

[Table 1 about here]

Among series A respondents (the closer relationship to the deceased), $18.0 \%$ were spouses, and there were no spouses in the B series (Table 2). Although spouses were unavailable for several cases, the spouse is not necessarily a closer relationship than a parent or sibling. Series B was more likely to include in-laws and other more distant relations—namely, aunts, uncles, nephews, nieces, cousins, neighbours and friends.

[Tables 2 about here]

Patterns of distress (PD) 
Tension was the most popular category of distress for index suicides, reported either by one or both respondents (82.0\%). The majority of respondent pairs agreed (58.0\%) (Table 3). Next most frequently reported categories of distress were sadness (64.0\%), various behavioural problems (e.g., antisocial behaviour, criminality) (66.0\%), marital conflict (62.0\%) and financial problems (62.0\%). Instances of the highest case-level agreement were for desertion, substance abuse, bereavement, marital problems, and both physical and verbal abuse.

\section{[Table 3 about here]}

For grouped categories of distress, which were computed from coded categories referring to a broader concept than coded categories, series-level agreement was relatively high. Case-level agreement was relatively higher for interpersonal conflict and victimization, but lower for physical health problems, mental-emotional problems, behavioural problems, and unfulfilled expectations.

Coded categories with both high series-level and case-level agreement included marital problems and financial problems. High series-level agreement, however, did not necessarily correspond to high case-level agreement (e.g., in-law conflicts, financial problems and hearing voices), based on analysis with the kappa statistic. Serious mental illness, referring to a local-language (Marathi) term (veda), was relatively low for both seriesand case-level agreement. It was more frequent in the series A interviews.

An explanation of the suicide based on poverty and joblessness of someone else in the family had low case-levels of agreement. A-series respondents tended to refer to an acute financial event or something different altogether instead of the context of poverty. For example, a B-series respondent (sister-in-law of the index suicide) referred to the context of limited resources: "She was always worried that her kids did not have enough to eat. They were always short of money. Even the house was not in a good condition ... but they could not afford repairs." The A-series respondent (an aunt who had supported the deceased) 
referred to acute financial stress from marital problems: "She must have quarrelled with him because of financial difficulties resulting from his addiction and got frustrated and finally committed suicide."

In another example, a neighbour (B-series), emphasized the impact of poverty: "Her husband would spend most of their money on alcohol. They were really poor. The children did not have much to eat. They would not have proper clothes to wear and the house was in a bad shape." The husband (A-series respondent) explained that suicide as a result of mental illness: "I think it was because of her mental illness that she got such a thought. She was not taking her medications properly."

Although case-level agreement was high for marital problems, it was relatively lower for other family conflicts. Joblessness in the family had the lowest levels of both series- and case-levels of agreement, and it was reported more frequently in the B-series interviews. For example, the sister-in-law of the deceased (B-series) referred to the joblessness of the deceased husband and its impact on the family:

She was bothered most of the time about her husband's job. He would sometimes have a job and sometime he was without one. But he would not even allow her to work. She was always worried that her kids did not have enough to eat. They were always short of money."

The A-series respondent for this case, however, acknowledged the family problems, the role of alcohol, and suggested the possible influence of an extramarital affair. She was more reluctant, however, to blame the husband:

She must have had a quarrel with her husband.... She must have done it in a fit of anger. She must have done it to punish her husband. She had in fact incriminated the husband who is now in jail for this. But I don't think it is husband's fault. It is basically her own quick temper.

Perceived causes $(P C)$ 
Reports of perceived causes complemented respondents' references to underlying problems, related suffering and distress. Financial problems, alcohol and marital problems were the most frequent perceived causes, each reported for at least half of the index suicides. Among these perceived causes, case-level agreement was highest for alcohol and marital problems (Table 4). Tension was less frequently identified as a perceived cause than it was as a feature of suffering and distress. Case-level agreement for tension as a perceived cause was low. Personality, work problems, and demons or sorcery were mentioned for at least a quarter of the index suicides, but these were also nonspecific with relatively low case-level agreement. Series-level disagreement was significant for victimization by violence (more in B-series interviews) and for heredity (more in A-series interviews). All 4 cases for which a series-A respondent identified victimization were also mentioned by the series-B respondent. Nonspecific perceived causes, indicated by the lowest levels of case-level agreement for PCs, were found for work problems, fate, family problems, heredity, other interpersonal conflict, demons, tension and overwork-exertion (Kappa $<0.15$ for each).

\section{Table 4 about here}

Help seeking

Among reported prior sources of self-help, support from family, prayer and temple visits were reported by more than half of index suicides for the underlying problems, as was prior consultation of a general physician among outside sources of help (Table 5).

Consulting a mental health specialist was relatively infrequent, reported for only 2 suicides, and Ayurveda and herbal medicines were reported for 1 each. There was a significant group level difference in identifying no outside help seeking — more frequently in the series B interviews (48.0\%) than series A (32.0\%). The case-level disagreement was highest for reports of no self-help. Additional general, nonspecific problem-solving efforts were reported 
most frequently (70.0\%) and considered desirable, with $40.0 \%$ agreement and fair to moderate case-level agreement (Kappa $=0.40)$.

\section{Table 5 about here}

Other features of suicide

Feelings of desperation (68.0\%), that is, a sense of no way out of a bad situation, and accounts of self-directed anger (58.0\%) were reported for more than half of the suicides (table not shown). There was no clear pattern of agreement. The influence of alcohol as a contributing factor was reported for $30.0 \%$ of suicides, and there was high case-level agreement $(\mathrm{kappa}=0.71)$. While many respondents accepted the idea that suicide indicates mental illness (reported in one or both interviews for $74.0 \%$ of index suicides), for $50.0 \%$ of cases the response differed. Mental tension was a reported feature of the condition for nearly all suicides $(96 \%)$ but with low case-level agreement $($ kappa $=0.08)$.

\section{Discussion}

Other studies have indicated the relevance of psychological and sociocultural autopsy to clarify the context and motivation of underlying problems and the perceived causes of individual and community patterns of suicide (Manoranjitham et al., 2010; Parkar et al., 2009). Although not its primary focus, our study highlights and builds on some notable features of suicide in a slum community of Mumbai, which reflect local social and cultural conditions, such as higher rates and indicated risk of women for suicide identified from police records. This study, however, was more notable as an initial effort to consider the influence of various perspectives in shaping the views of different survivors of a single index suicide. It shows how a single account may be similar or diverge from others, and how such explanations of suicide may reflect a perspective defined, or at least influenced, by the relationship of an informant to the deceased. Our findings highlight the consistency and discrepancy of particular explanations of suicide within a community and for particular relationships. Acknowledgement of the relevance of diversity and perspectivism helps to 
unravel the complexity of determinants of suicide and the burden of related mental health and social problems that require attention for population-based strategies for community mental health (Jacob, 2008).

Even mental health professionals have diverse views about the nature of suicide as the result of biological, psychological, cognitive and social determinants, which guide various distinct orientations to research. Inasmuch as such diverse views exist in professional communities, why not also in lay communities? In clinical assessment, the value of the contribution of multiple sources for clinical and family history is well-established, and it routinely motivates consideration of family inputs in clinical psychiatric practice in India. For some clinical problems this is likely to be relatively more or less critical in a particular case formulation. Based on a comparable interest, our study indicates the value of a community cultural formulation of suicide informed by multiple sources within a community. Our findings indicate aspects of such a cultural formulation that are relatively more consistent and others that are relatively less so within communities.

Family history has long been a valued feature of clinical assessment, and this study shows how consideration of the distance of broadly defined kinship relationships contributes to perspectivist accounts of suicide. Although this adds useful information, sufficient consistency in previous findings and the recommendation for additional and more routine use of sociocultural autopsies remains valid (Parkar et al., 2009). The current study highlights the additional value of acknowledging and considering the source of information. Further research on alternative explanations of suicide will contribute to the interpretation of data from recommended surveillance of suicides.

Distinguishing series-level and case-level agreement

Our study design enabled us to clarify two complementary features of the consistency and differences in ways of explaining suicide. Series-level agreement referred to common recurring ideas in the community about the reasons for suicide, which are not necessarily associated with consistent attribution for particular index cases of suicide. Case- 
level agreement referred to agreement for these particular index cases of suicide. Our findings suggest that specific explanations of the cause may be less open to variable or diverse interpretation for some suicides (high case-level agreement). The popular appeal of some explanations, on the other hand, may also be less specific to particular cases than for explaining suicide in general terms in the community (series-level agreement).

For example, tension, a locally preferred category of distress (Parkar et al., 2003), was a feature of suicide reported frequently as an underlying problem in both groups by most respondents. It was also identified as a perceived cause by an equal percentage of both groups (30\%), but despite high series-level agreement, case-level agreement was low $(\mathrm{kappa}=0.14)$. Other relationships between series- and case-level agreement are also instructive. The influence of alcohol as a perceived cause of suicide had high levels of both series-level and case-level agreement, and the agreed acknowledgement of the influence of alcohol also shows that professional and community views are consistent in that regard. Unlike alcohol as a reliably identifiable feature of particular suicides, tension referred to a culturally preferred style of expressing problems and distressing emotions, with relatively low agreement for index cases as a perceived cause.

Although our study findings indicate the appeal of a relationship between suicide and mental illness, the role of acknowledged mental illness for particular cases was relatively nonspecific. There was very high series-level agreement among community respondents for the assertion that suicide indicates mental illness, supported by $50.0 \%$ of series $A$ and $48.0 \%$ of series B respondents, but there was considerable diversity on this point with regard to case-level disagreement $(k a p p a=0.00)$. Mental illness was identified as a perceived cause for $22.0 \%$ of suicides by a respondent in either group, but case-level agreement was only $6.0 \%$ (table 3). Our findings show that mental illness and mental tension were recognized as high-risk conditions but relatively non-specific and unreliable in the analysis of case-level agreement. Community views may therefore be regarded as a challenge to the professional emphasis on the formulation of suicide as explainable and preventable by identifying and treating mental illness. 
Explanations of suicide in this urban slum also demonstrated some interesting features with regard to the cultural meaning of suicide, which are relevant for transcultural study. The frequency of desperation and self-directed anger, reported by at least one of the two respondents for more than half of index suicides, suggests a community view consistent both with Freudian concepts of retroflected anger and suicide (Freud, 1957) and Shneidman's concept of psychache (Shneidman, 1998).

Features of suicide based on the relationship of survivor respondents

The analysis of agreement showed that some features of suicide were more likely to be reported by one or the other series of respondents. Differences in the priority of a particular category of explanation may refer either to an interest or bias for socially acceptable ways of explaining suicide. For example, the series-A respondents (closer relatives of the index suicides) focussed on acute events threatening livelihood and financial viability, such as joblessness, compared to the series-B respondents, who were more likely to refer to the impact of enduring poverty. The series-A respondents were more reluctant to refer to the context of deprivation, thereby preserving social standing and prestige. This was less of a personal threat for more distant series-B relationships.

Specific relationships shape survivor views. The accounts of a mother and mother-inlaw may be contradictory, based on the different interests and expectations of each, and the nature of the relationship with the deceased may be expected to influence the meaning of the suicide for other relationships as well. Parents, siblings, spouses, and in-laws may each have a distinct set of interests and feelings about the deceased and reasons for suicide, which influence interpretation of the suicidal event. Victimization was reported more frequently by the B-series respondents, who are likely to be held relatively less accountable for that. Perhaps this may have also motivated the preference among A-series respondents for heredity, because it indicates a problem of the individual, rather than social stressors of the family setting, for which the family may be culpable. Other features of suicide, including 
desperation (intense feelings of 'no way out'), self-directed anger and impulsivity also tended to be reported more by series $A$.

Another reason for discrepancies, apart from the orientation and bias of the respondent group, may refer to their access to information about the index suicide. This would explain why series-B respondents more frequently reported no outside help seeking than series A. Differences in access to information about coping strategies of index suicides may also account for the lowest case-levels of agreement reported for no prior self-help.

Marital conflicts are generally more intense, stressful and public than other interpersonal conflicts. Desertion, which is an especially intense feature of marital conflict, is highly visible to the community, and it had very high case-level agreement (kappa $=0.90)$; general marital conflict short of desertion also had high case-level agreement $(k a p p a=$ 0.71). We also found that other marriage-related and marriage-seeking family issues (namely, problems with in-laws and failed romance) both had high agreement among perceived causes. Marital problems are likely to be related to many other issues beyond the relationship, especially in Indian culture, and the potential of marriage as a stressor and cause of suicide has been widely acknowledged (Bhatia, Khan, Mediratta \& Sharma, 1987). Although marital problems are also a recognized risk for suicide in Europe and North America (Loehr \& Schmidtke, 2004), the ways in which these problems impose risk are appropriate topics of interest for further cross-cultural study.

Among other interpersonal conflicts apart from marital relations, the category of other family conflicts, which is more likely to be manifest in the privacy of the home, had a low level of agreement $(k a p p a=0.13)$. Overwork-exertion, other work problems, unemployment and even financial problems-which may all be less public and less visible-had low caselevels of agreement. Sexual behaviour and heredity were more likely to be identified by series $A$.

Limitations of this study and implications for further research 
Silverman (2004) highlights the need to consider the relevance of perspectives from which explanations of suicide arise. Vulnerability to the impact of the loss, questions of support and compensation, legal culpability may all influence explanations of suicide reported by survivors. Although our analysis clarifies an approach and identifies features of community-level and case-level explanations and features of suicide for family and community survivors, it is limited by the sampling strategy. Larger studies with more specific selection criteria are needed to distinguish series $A$ and series $B$ respondents.

Our identification of index suicides by police records is known to underestimate total suicides in a community because of medical-legal implications and stigma (Manoranjitham et al., 2010). Just as incentives to report murders as suicides to reduce culpability, suicides may be reported as accidental or natural deaths. This point, however, is more likely to reduce the validity of surveillance data than to affect our comparison of respondent accounts, which was the focus of this study, although confounding is possible. Alternatives to reliance on policy records in other settings have been productive. Establishing a presence in a community enabling active surveillance has been shown to be more effective than passive surveillance, such as police records, to identify cases (Aaron, Joseph, Abraham, Muliyil, George, Prasad et al., 2004). We might expect that underlying problems and triggers for such cases would be more likely to be contested, inasmuch as the status of the suicide itself was sufficiently contested to keep the case out of the official register.

Although we have considered the relationship between closest and less close survivor groups, further study of the features of particular survivor groups will benefit from the methods developed in this study. Robeiro and Joiner (Ribeiro \& Joiner, 2009) highlight the need for research in the field to identify parameters and constructs that confer risk. Further research in which the comparison groups comprise specific kinship relationships to the deceased would also test the findings from this study, which may be regarded as suggestive but still requiring further validation.

The approach we suggest, focusing on underlying problems and perceived causes will help to identify and compare risk factors with reference to theory, as Robeiro and Joiner 
suggest, for comparison across cultures and as a practical matter to guide community interventions. Additional research based on these interests is also needed to show how common and distinctive views are shaped by specific interests based on survivors' relationships to an index suicide.

\section{Practical implications for prevention}

Suicide is essentially a product of both psychological and sociocultural factors, for which, like all aspects of health, ecosocial factors are also relevant (Krieger, 2001). Furthermore, one cannot assume that global strategies for prevention will work everywhere without attending to the local features of suicide. Inattention to this point helps to explain why the current body of research has not fulfilled expectations for reducing suicide, and why the scope and framework for assessment still does not adequately guide formulation of effective interventions. Suicide surveillance data currently are too frequently limited by a focus on rates, demographic features (Milner, McClure \& De Leo, 2010) and diagnostics. They do not adequately consider the context and motivation of underlying problems and perceived causes or critically evaluate the impact of help seeking (Bastia \& Kar, 2009). Influential accounts of suicide illustrate the point. In a chapter entitled, Barriers to effective treatment and intervention, in a report of the U.S. Institute of Medicine, mental disorder is linked to 90$95 \%$ of suicides, and barriers are identified as stigma and discrimination, financial barriers, and barriers to accessing mental health services (Goldsmith et al., 2002). Sociocultural autopsies acknowledging the source of information about deaths by suicide would be a relevant assessment to complement verbal autopsies in health demographic surveillance.

Data from the WHO world mental health surveys confirms a relationship between mental disorder and suicide (Nock, Hwang, Sampson, Kessler, Angermeyer, Beautrais et al., 2009), and an emphasis on the strategy for preventing suicide by identifying and treating high-risk mental disorders is clinically appropriate. But the approach has long been known to be inadequate for explaining and reducing suicide in the general population (Knox, Conwell \& Caine, 2004; Murphy, 1983). The WHO world mental health survey data also support 
important relationships between trauma and suicide (Stein, Chiu, Hwang, Kessler, Sampson, Alonso et al., 2010) and between chronic illness and suicide (Scott, Hwang, Chiu, Kessler, Sampson, Angermeyer et al., 2010). Manoranjitham and colleages (Manoranjitham et al., 2010) explain why a focus on psychiatric disorders is unlikely to reduce suicide rates in the population, especially in high-stress settings of limited resources. Although the assertion that mental health is more than the absence of mental disorder is widely acknowledged, it is also widely ignored in planning for the mental health of populations, and it requires more careful consideration in planning for suicide prevention (De Leo, 2002).

In Japan, widespread agreement that "national efforts to tackle the problem [of increasing suicide] are not working" contrast sharply to disputes about the reasons for that, and cultural factors have been suggested (McCurry, 2010). Social, cultural and environmental features of mental health also require attention, particularly in India and lowand middle-income countries generally. Jacob (2008) develops this argument, noting that, "Individual approaches will help people in distress and prevent individuals from committing suicide, but will not reduce population suicide rates."

Milner and de Leo (2010) argue that encouraging research may be the best approach for stimulating the suicide prevention agenda in developing countries. Our research clarifies common local patterns of suicide in an urban slum of Mumbai, and indicates those aspects of social and cultural determinants that require consideration of the interests and perspective of respondents. Although the importance of taking multiple sources into account in the course of social history and risk assessment is already acknowledged, questions about diversity in accounts have not previously been considered for explaining suicide in study of the broader interests of psychological autopsy. Inasmuch as suicide represents a final common pathway of mental ill health (Hawton, 1998), our findings may also be relevant for history taking to clarify contexts of mental health problems and risk for suicide. For example, the role of family problems and victimization were less likely to be reported by group-B (less close) respondents than group A. Our study indicates that the absence of such factors in a survivor account, even a family survivor close to the deceased, should be corroborated. 
Information and guidance from sociocultural autopsy studies and surveillance should be available not only to psychiatrists, doctors and other health professionals, but also to paraprofessionals who are important resources for mental health in communities-e. g., women's groups (mahila mandals), child caretakers (anganwadi), microfinance groups, supportive empowerment groups (e.g., Mahila Bachat Gat in Maharashtra) and religious associations.

\section{Conclusion}

Our findings indicate the relevance of comparing preferred explanations of suicide generally and case-based causes with reference to the relative closeness of respondents explaining the cause of an index suicide. Serious mental illness, the standard professional explanation, was identified as a cause of suicide for $22.0 \%$ of index cases, but there was agreement for only $6.0 \%$. The study shows how survivor accounts of suicide reflect not only the event itself, but also the vantage point of the respondent, and one or the other may predominate for different cases and for different explanations. Multiple corroborating assessment s may be less important for appreciating the role of some explanations, such as alcohol misuse, and more important for appreciating the role of interpersonal conflicts (apart from marital conflict)—especially with in-laws, spouse and parent-child conflict.

Comparing the frequency and prominence, which are quantitative features of categories reported, and the narrative content of two groups of survivor respondents indicated the value of a mixed methods approach. Quantitative and qualitative data each identify and overcome limitations of the other. As Trostle explains, qualitative methods for interdisciplinary collaboration of epidemiology and anthropology "can increase conceptual clarity and analytic quality" (Trostle, 2005).

Interest in clarifying sociocultural features and vulnerabilities, and acknowledging different survivor interests, should guide development of useful study of suicide. Our discussion recommends the value of integrating sociocultural autopsies, which acknowledge the relationship of survivor informants, as a complement for verbal autopsies in the 
operations of health demographic surveillance sites. Further research, surveillance and consideration in cohort study planning are needed in other urban and rural communities of India and elsewhere. Such research should clarify not only social and cultural problems and precipitants of suicide, but also determinants of consistency and divergence in survivor accounts. Our experience and findings are relevant for enabling the next generation of suicide assessments to contribute more effectively to suicide prevention and broader interests of mental health. 


\section{REFERENCES}

Aaron, R., Joseph, A., Abraham, S., Muliyil, J., George, K., Prasad, J., Minz, S., Abraham, V. J., \& Bose, A. (2004). Suicides in young people in rural southern India. The Lancet, 363(9415), 1117-1118.

Appleby, L., Dennehy, J. A., Thomas, C. S., Faragher, E. B., \& Lewis, G. (1999). Aftercare and clinical characteristics of people with mental illness who commit suicide: a case-control study. Lancet, 353(9162), 1397-1400.

Bastia, B. K., \& Kar, N. (2009). A psychological autopsy study of suicidal hanging from Cuttack, India: focus on stressful life situations. Arch Suicide Res, 13(1), 100-104.

Beautrais, A. L. (2001). Suicides and serious suicide attempts: two populations or one? Psychol Med, 31(5), 837-845.

Bertolote, J. M., Fleischmann, A., De Leo, D., \& Wasserman, D. (2004). Psychiatric diagnoses and suicide: revisiting the evidence. Crisis, 25(4), 147-155.

Bhatia, S. C., Khan, M. H., Mediratta, R. P., \& Sharma, A. (1987). High risk suicide factors across cultures. Int J Soc Psychiatry, 33(3), 226-236.

Cavanagh, J. T., Owens, D. G., \& Johnstone, E. C. (1999). Suicide and undetermined death in south east Scotland. A case-control study using the psychological autopsy method. Psychol Med, 29(5), 1141-1149.

Chowdhury, A. N., Shashmal, R., Dutta, S. K., \& Weiss, M. G. (2004). Ethnographic survey of deliberate self-harm in some villages of Sundarban Delta, West Bengal. J Indian Anthrop Soc, 39 173-182.

Conner, K. R., Beautrais, A. L., Brent, D. A., Conwell, Y., Phillips, M. R., \& Schneider, B. (2011). The next generation of psychological autopsy studies. Part I. Interview content. Suicide Life Threat.Behav., 41(6), 594-613.

Conner, K. R., Beautrais, A. L., Brent, D. A., Conwell, Y., Phillips, M. R., \& Schneider, B. (2012). The Next Generation of Psychological Autopsy Studies: Part 2. Interview Procedures. Suicide Life Threat.Behav.

De Leo, D. (2002). Why are we not getting any closer to preventing suicide? Br J Psychiatry, 181 372-374.

Freud, S. (1957). Mourning and melancholia. Standard Edition, 14: 237-258. London: Hogarth Press.

Gajalakshmi, V., \& Peto, R. (2006). Commentary: verbal autopsy procedure for adult deaths. International Journal of Epidemiology, 35(3), 748-750.

Goldsmith, S. K., Pellmar, P. C., Kleinman, A. M., \& Bunney, W. E. (2002). Reducing suicide: a national imperative. Washington, D.C.: National Academies Press.

Harris, E. C., \& Barraclough, B. (1997). Suicide as an outcome for mental disorders. A meta-analysis. Br J Psychiatry, 170 205-228.

Hawton, K. (1998). A national target for reducing suicide. Important for mental health strategy as well as for suicide prevention. BMJ, 317(7152), 156-157. 
Jacob, K. S. (2008). The prevention of suicide in India and the developing world: the need for population-based strategies. Crisis, 29(2), 102-106.

Knox, K. L., Conwell, Y., \& Caine, E. D. (2004). If suicide is a public health problem, what are we doing to prevent it? Am J Public Health, 94(1), 37-45.

Krieger, N. (2001). Theories for social epidemiology in the 21st century: an ecosocial perspective. International Journal of Epidemiology, 30(4), 668-677.

Lewins, A., \& Silver, C. (2007). Qualitative coding in software: principles and processes.Using software in qualitative research: a step-by-step guide (pp.81-90). Los Angeles: Sage Publications.

Loehr, C., \& Schmidtke, A. (2004). Marital relations of suicide attempters. Cambridge/GÃ $\mid t t i n g e n:$ Hogrefe \& Huber.

Ludbrook, J. (2002). Statistical techniques for comparing measurers and methods of measurement: a critical review. Clin.Exp.Pharmacol.Physiol, 29(7), 527-536.

Manoranjitham, S. D., Rajkumar, A. P., Thangadurai, P., Prasad, J., Jayakaran, R., \& Jacob, K. S. (2010). Risk factors for suicide in rural south India. Br.J.Psychiatry, 196(1), 26-30.

McCurry, J. (2010). Japan to rethink suicide-prevention policies : The Lancet. Lancet, 371(9630), 2071.

Milner, A., \& De Leo, D. (2010). Suicide research and prevention in developing countries in Asia and the Pacific. Bull World Health Organ, 88(10), 795-796.

Milner, A., McClure, R., \& De Leo, D. (2010). Socio-economic determinants of suicide: an ecological analysis of 35 countries. Soc Psychiatry Psychiatr.Epidemiol., In Press.

Murphy, G. E. (1983). On suicide prediction and prevention. Arch Gen Psychiatry, 40(3), 343-344.

Nock, M. K., Hwang, I., Sampson, N., Kessler, R. C., Angermeyer, M., Beautrais, A., Borges, G., Bromet, E., Bruffaerts, R., de Girolamo, G., de Graaf, R., Florescu, S., Gureje, O., Haro, J. M., Hu, C., Huang, Y., Karam, E. G., Kawakami, N., Kovess, V., Levinson, D., Posada-Villa, J., Sagar, R., Tomov, T., Viana, M. C., \& Williams, D. R. (2009). Cross-national analysis of the associations among mental disorders and suicidal behavior: findings from the WHO World Mental Health Surveys. PLoS Med, 6(8), e1000123.

Parkar, S. R., Dawani, V., \& Weiss, M. G. (2006). Clinical diagnostic and sociocultural dimensions of deliberate self-harm in Mumbai, India. Suicide Life Threat.Behav., 36(2), 223-238.

Parkar, S. R., Dawani, V., \& Weiss, M. G. (2008). Gender, suicide, and the sociocultural context of deliberate self-harm in an urban general hospital in Mumbai, India. Cult.Med.Psychiatry, 32(4), 492515.

Parkar, S. R., Fernandes, J., \& Weiss, M. G. (2003). Contextualizing mental health: gendered experiences in a Mumbai slum. Anthropology \& Medicine, 10(3).

Parkar, S. R., Nagarsekar, B., \& Weiss, M. G. (2009). Explaining suicide in an urban slum of Mumbai, India: a sociocultural autopsy. Crisis, 30(4), 192-201.

Parry, J. P. (1994). Death in Banaras. Cambridge Univ Pr.

Phillips, M. R., Yang, G., Zhang, Y., Wang, L., Ji, H., \& Zhou, M. (2002). Risk factors for suicide in China: a national case-control psychological autopsy study. Lancet, 360(9347), 1728-1736. 
Phillips, M. (2004). Suicide prevention in developing countries: where should we start? World Psychiatry, 3(3), 156-157.

Ribeiro, J. D., \& Joiner, T. E. (2009). The interpersonal-psychological theory of suicidal behavior: current status and future directions. J Clin.Psychol, 65(12), 1291-1299.

Sainath, P. (2010). 17,368 farm suicides in 2009. Chennai.

Scott, K. M., Hwang, I., Chiu, W. T., Kessler, R. C., Sampson, N. A., Angermeyer, M., Beautrais, A., Borges, G., Bruffaerts, R., de Graaf, R., Florescu, S., Fukao, A., Haro, J. M., Hu, C., Kovess, V., Levinson, D., Posada-Villa, J., Scocco, P., \& Nock, M. K. (2010). Chronic physical conditions and their association with first onset of suicidal behavior in the world mental health surveys. Psychosom Med, 72(7), 712-719.

Shneidman, E. S. (1998). Perspectives on suicidology. Further reflections on suicide and psychache. Suicide Life Threat.Behav., 28(3), 245-250.

Silverman, M. M. (2004). Preventing suicide: a call to action. World Psychiatry, 3(3), 152-153.

Stein, D. J., Chiu, W. T., Hwang, I., Kessler, R. C., Sampson, N., Alonso, J., Borges, G., Bromet, E., Bruffaerts, R., de Girolamo, G., Florescu, S., Gureje, O., He, Y., Kovess-Masfety, V., Levinson, D., Matschinger, H., Mneimneh, Z., Nakamura, Y., Ormel, J., Posada-Villa, J., Sagar, R., Scott, K. M., Tomov, T., Viana, M. C., Williams, D. R., \& Nock, M. K. (2010). Cross-national analysis of the associations between traumatic events and suicidal behavior: findings from the WHO World Mental Health Surveys. PLoS One, 5(5), e10574.

Trostle, J. A. (2005). Epidemiology and culture. Cambridge: Cambridge University Press.

Trostle, J. A. (2008). International encyclopedia of public health. In K. Heggenhougen, \& S.R. Quah (Eds.), (pp.48-56). Amsterdam; Elsevier.

Vijayakumar, L., John, S., Pirkis, J., \& Whiteford, H. (2005). Suicide in developing countries (2): risk factors. Crisis, 26(3), 112-119.

Weiss, M. G. (1997). Explanatory Model Interview Catalogue (EMIC): Framework for Comparative Study of Illness. Transcultural Psychiatry, 34(2), 235-264.

Weiss, M. G. (2001). Cultural epidemiology: an introduction and overview. Anthropology \& Medicine, 8(1), 5-29. 
Table 1. Sample characteristics of index suicide cases.

\begin{tabular}{lrrr}
\hline Sample characteristics & $\begin{array}{r}\text { Women } \\
\mathbf{( 2 8 )}\end{array}$ & $\begin{array}{r}\text { Men } \\
\mathbf{( 2 2 )}\end{array}$ & $\begin{array}{r}\text { Total } \\
\mathbf{( 5 0 )}\end{array}$ \\
\hline Age & 28.9 & 31.9 & 30.2 \\
\hline Mean & 10.3 & 10.7 & 10.5 \\
\hline S.D. & 11 & 10 & 10 \\
\hline Min & 55 & 50 & 55 \\
\hline Max & & & \\
\hline Marital Status & 3 & 6 & 9 \\
\hline Never Married & 20 & 12 & 32 \\
\hline Married & 2 & 2 & 4 \\
\hline Separated or divorced & 2 & 1 & 3 \\
\hline Remarried & 1 & 1 & 2 \\
\hline Widowed & & & \\
\hline Education & 15 & 5 & 20 \\
\hline None & 4 & 7 & 11 \\
\hline Primary & 8 & 9 & 17 \\
\hline Secondary & 1 & 1 & 2 \\
\hline Beyond secondary & & & \\
\hline Religion & 17 & 12 & 29 \\
\hline Hindu & 5 & 6 & 11 \\
\hline Muslim & 6,496 & 3,474 & 3,487 \\
\hline Buddhist & 2,058 & 2,376 & 2,169 \\
\hline Family Income & 1,000 & 1,000 & 1,000 \\
\hline Mean & 8,000 & 9,500 & 9,500 \\
\hline S.D. & & & 10 \\
\hline Min & & & \\
\hline Max & & & \\
\hline & & & \\
\hline
\end{tabular}


Table 2. Sample characteristics of survivor respondents

\begin{tabular}{lrr}
\hline \multicolumn{2}{l}{ Series A } & Series B \\
\hline Relationship to deceased* & & \\
\hline Parents & 11 & 4 \\
\hline Siblings & 11 & 9 \\
\hline In-laws & 9 & 16 \\
\hline Spouse & 9 & 0 \\
\hline Child & 3 & 5 \\
\hline Other relations & 3 & 7 \\
\hline Neighbours and friends & 4 & 9 \\
\hline Sex & & \\
\hline Male & 18 & 14 \\
\hline Female & 32 & 36 \\
\hline Age & & \\
\hline Mean ( \pm sd) & 37.7 & 30.6 \\
\hline S.D. & 13.6 & 12.4 \\
\hline Min & 17 & 16 \\
\hline Max & 70 & 80 \\
\hline
\end{tabular}

*Relationship to each index case of series $A$ and $B$ respondents was different. 
Table 3. Frequency and agreement for indicated categories of distress reported in two series of suicide survivor interviews $(n=50)$.

\begin{tabular}{|c|c|c|c|c|c|c|c|}
\hline Indicated categories of distress & $\begin{array}{c}\text { Total } \\
\text { reported }\end{array}$ & Agreed & $\begin{array}{l}\text { Series A } \\
\text { reported }\end{array}$ & $\begin{array}{l}\text { Series B } \\
\text { reported }\end{array}$ & $\begin{array}{l}\text { Fraction } \\
\text { agreed }\end{array}$ & $\begin{array}{c}\text { McNemar } \\
\text { test }\end{array}$ & $\begin{array}{c}\text { Kappa } \\
\text { statistic }\end{array}$ \\
\hline & $\%$ & $\%$ & $\%$ & $\%$ & & P-Value & Estimate \\
\hline PHYSICAL HEALTH PROB & 44.0 & 16.0 & 32.0 & 28.0 & 0.36 & 0.593 & 0.33 \\
\hline Chronic disease (self) & 32.0 & 16.0 & 28.0 & 20.0 & 0.50 & 0.157 & 0.57 \\
\hline Disease/Injury (self) & 14.0 & 2.0 & 6.0 & 10.0 & 0.14 & 0.414 & 0.19 \\
\hline MENTAL-EMOTIONAL PROB & 88.0 & 66.0 & 76.0 & 78.0 & 0.75 & 0.763 & 0.38 \\
\hline Tension-Worry & 82.0 & 58.0 & 74.0 & 66.0 & 0.71 & 0.248 & 0.43 \\
\hline Sadness & 64.0 & 34.0 & 46.0 & 52.0 & 0.53 & 0.439 & 0.40 \\
\hline Hearing voices & 12.0 & 2.0 & 6.0 & 8.0 & 0.17 & 0.655 & 0.23 \\
\hline Serious mental illness (veda) & 22.0 & 6.0 & 18.0 & 10.0 & 0.27 & 0.157 & 0.34 \\
\hline Bereavement & 6.0 & 4.0 & 4.0 & 6.0 & 0.67 & 0.317 & 0.79 \\
\hline BEHAVIOURAL PROB & 90.0 & 68.0 & 78.0 & 80.0 & 0.76 & 0.763 & 0.34 \\
\hline Substance abuse (other) & 32.0 & 16.0 & 26.0 & 22.0 & 0.50 & 0.480 & 0.56 \\
\hline Substance abuse (self) & 40.0 & 32.0 & 36.0 & 36.0 & 0.80 & 1.000 & 0.83 \\
\hline Other behavioural & 66.0 & 30.0 & 46.0 & 50.0 & 0.45 & 0.637 & 0.28 \\
\hline UNFULFILLED EXPECTATIONS & 76.0 & 40.0 & 60.0 & 56.0 & 0.53 & 0.637 & 0.26 \\
\hline Job or business (self) & 42.0 & 18.0 & 30.0 & 30.0 & 0.43 & 1.000 & 0.43 \\
\hline Job or business (other family) & 26.0 & 2.0 & 8.0 & 20.0 & 0.08 & 0.083 & 0.03 \\
\hline Financial problem & 62.0 & 26.0 & 44.0 & 44.0 & 0.42 & 1.000 & 0.27 \\
\hline Poverty & 18.0 & 2.0 & 8.0 & 12.0 & 0.11 & 0.480 & 0.12 \\
\hline INTERPERSONAL CONFLICT & 86.0 & 70.0 & 78.0 & 78.0 & 0.81 & 1.000 & 0.53 \\
\hline Parent & 14.0 & 4.0 & 12.0 & 6.0 & 0.29 & 0.180 & 0.40 \\
\hline In-laws & 10.0 & 2.0 & 6.0 & 6.0 & 0.20 & 1.000 & 0.29 \\
\hline Spouse & 62.0 & 48.0 & 54.0 & 56.0 & 0.77 & 0.706 & 0.72 \\
\hline Siblings & 28.0 & 6.0 & 14.0 & 20.0 & 0.21 & 0.366 & 0.23 \\
\hline Other family & 18.0 & 2.0 & 14.0 & 6.0 & 0.11 & 0.157 & 0.13 \\
\hline Romantic problem & 14.0 & 4.0 & 10.0 & 8.0 & 0.29 & 0.655 & 0.39 \\
\hline Other interpersonal & 16.0 & 6.0 & 12.0 & 10.0 & 0.38 & 0.655 & 0.49 \\
\hline VICTIMISATION & 56.0 & 32.0 & 48.0 & 40.0 & 0.57 & 0.248 & 0.52 \\
\hline Physical abuse & 26.0 & 14.0 & 18.0 & 22.0 & 0.54 & 0.414 & 0.63 \\
\hline Verbal abuse & 42.0 & 22.0 & 34.0 & 30.0 & 0.52 & 0.527 & 0.54 \\
\hline Desertion & 12.0 & 10.0 & 12.0 & 10.0 & 0.83 & 0.317 & 0.90 \\
\hline OTHER & 76.0 & 38.0 & 58.0 & 56.0 & 0.50 & 0.819 & 0.23 \\
\hline Other & 58.0 & 18.0 & 40.0 & 36.0 & 0.31 & 0.655 & 0.15 \\
\hline Cannot say & 44.0 & 14.0 & 26.0 & 32.0 & 0.32 & 0.439 & 0.27 \\
\hline
\end{tabular}

Only categories reported by more than $5 \%$ ( $\geq 3$ respondents) in at least one series are listed. Grouped categories in caps may include additional categories. Agreement refers to identification by both respondents. Pvalue of McNemar test indicates series-level agreement and estimate of kappa statistic indicates case-level agreement. 
Table 4. Frequency and agreement for perceived causes reported in two series of suicide survivor interviews $(n=50)$.

\begin{tabular}{|c|c|c|c|c|c|c|c|}
\hline Perceived cause & $\begin{array}{c}\text { Total } \\
\text { reported }\end{array}$ & Agreed & $\begin{array}{l}\text { Series A } \\
\text { reported }\end{array}$ & $\begin{array}{l}\text { Series B } \\
\text { reported }\end{array}$ & $\begin{array}{c}\text { Fraction } \\
\text { agreed }\end{array}$ & $\begin{array}{c}\text { McNemar } \\
\text { test }\end{array}$ & $\begin{array}{c}\text { Kappa } \\
\text { statistic }\end{array}$ \\
\hline & $\%$ & $\%$ & $\%$ & $\%$ & & P-Value & Estimate \\
\hline INGESTION & 58.0 & 38.0 & 46.0 & 50.0 & 0.66 & 0.527 & 0.60 \\
\hline Food/water & 6.0 & 0.0 & 4.0 & 2.0 & 0.00 & 0.564 & -0.03 \\
\hline Alcohol & 56.0 & 36.0 & 46.0 & 46.0 & 0.64 & 1.000 & 0.60 \\
\hline Abused drug & 10.0 & 4.0 & 8.0 & 6.0 & 0.40 & 0.564 & 0.54 \\
\hline INJURY-MEDICAL & 40.0 & 12.0 & 30.0 & 22.0 & 0.30 & 0.285 & 0.28 \\
\hline Medical illness & 24.0 & 6.0 & 16.0 & 14.0 & 0.25 & 0.739 & 0.29 \\
\hline Overwork / exertion & 16.0 & 2.0 & 10.0 & 8.0 & 0.13 & 0.706 & 0.15 \\
\hline Pregnancy related & 6.0 & 0.0 & 4.0 & 2.0 & 0.00 & 0.564 & -0.03 \\
\hline ENVIRONMENT & 8.0 & 4.0 & 6.0 & 6.0 & 0.50 & 1.000 & 0.65 \\
\hline Housing/living conditions & 8.0 & 4.0 & 6.0 & 6.0 & 0.50 & 1.000 & 0.65 \\
\hline SOCIAL CAUSES & 86.0 & 58.0 & 76.0 & 68.0 & 0.67 & 0.285 & 0.31 \\
\hline Failed romance & 10.0 & 6.0 & 8.0 & 8.0 & 0.60 & 1.000 & 0.73 \\
\hline Problems with spouse & 50.0 & 24.0 & 40.0 & 34.0 & 0.48 & 0.405 & 0.44 \\
\hline Problems with in-laws & 12.0 & 4.0 & 10.0 & 6.0 & 0.33 & 0.317 & 0.46 \\
\hline Other family problem & 22.0 & 2.0 & 10.0 & 14.0 & 0.09 & 0.527 & 0.06 \\
\hline Work problems & 32.0 & 2.0 & 14.0 & 20.0 & 0.06 & 0.439 & -0.06 \\
\hline Unemployment & 14.0 & 0.0 & 6.0 & 8.0 & 0.00 & 0.706 & -0.07 \\
\hline Other interpersonal conflict & 20.0 & 2.0 & 14.0 & 8.0 & 0.10 & 0.317 & 0.09 \\
\hline Financial problem / debt & 56.0 & 18.0 & 42.0 & 32.0 & 0.32 & 0.251 & 0.19 \\
\hline VICTIMISATION & 12.0 & 4.0 & 4.0 & 12.0 & 0.33 & 0.046 & 0.47 \\
\hline Victim of violence & 12.0 & 4.0 & 4.0 & 12.0 & 0.33 & 0.046 & 0.47 \\
\hline MAGIC-SPIRITS & 44.0 & 12.0 & 32.0 & 24.0 & 0.27 & 0.317 & 0.21 \\
\hline Sorcery & 28.0 & 6.0 & 18.0 & 16.0 & 0.21 & 0.763 & 0.22 \\
\hline Demons & 28.0 & 4.0 & 18.0 & 14.0 & 0.14 & 0.564 & 0.11 \\
\hline Other supernatural & 6.0 & 0.0 & 6.0 & 0.0 & 0.00 & - & \\
\hline PSYCHOLOGICAL & 68.0 & 28.0 & 50.0 & 46.0 & 0.41 & 0.655 & 0.20 \\
\hline Tension & 48.0 & 12.0 & 30.0 & 30.0 & 0.25 & 1.000 & 0.14 \\
\hline Personality & 40.0 & 14.0 & 26.0 & 28.0 & 0.35 & 0.782 & 0.34 \\
\hline HEREDITY & 24.0 & 2.0 & 20.0 & 6.0 & 0.08 & 0.035 & 0.07 \\
\hline Heredity & 24.0 & 2.0 & 20.0 & 6.0 & 0.08 & 0.035 & 0.07 \\
\hline SEXUAL & 8.0 & 0.0 & 8.0 & 0.0 & 0.00 & & \\
\hline FATE, WILL-OF-GOD & 10.0 & 2.0 & 6.0 & 6.0 & 0.20 & 1.000 & 0.29 \\
\hline Fate & 10.0 & 0.0 & 6.0 & 4.0 & 0.00 & 0.655 & -0.05 \\
\hline OTHER & 62.0 & 20.0 & 44.0 & 38.0 & 0.32 & 0.513 & 0.14 \\
\hline Other & 30.0 & 4.0 & 20.0 & 14.0 & 0.13 & 0.405 & 0.08 \\
\hline Cannot say & 44.0 & 12.0 & 26.0 & 30.0 & 0.27 & 0.617 & 0.21 \\
\hline
\end{tabular}

Only categories reported by more than $5 \%$ ( $\geq 3$ respondents) in at least one series are listed. Grouped categories in caps include additional categories. Agreement refers to identification by both respondents. Pvalue of McNemar test indicates series-level agreement and estimate of kappa statistic indicates case-level agreement. 
Table 5. Frequency and agreement for use of various sources of help reported in two series of suicide survivor interviews $(n=50)$.

\begin{tabular}{|c|c|c|c|c|c|c|c|}
\hline \multirow[t]{2}{*}{ Prior help } & $\begin{array}{c}\text { Total } \\
\text { reported }\end{array}$ & Agreed & $\begin{array}{l}\text { Series A } \\
\text { reported }\end{array}$ & $\begin{array}{l}\text { Series B } \\
\text { reported }\end{array}$ & $\begin{array}{c}\text { Fraction } \\
\text { agreed }\end{array}$ & $\begin{array}{c}\text { McNemar } \\
\text { test }\end{array}$ & $\begin{array}{c}\text { Kappa } \\
\text { statistic }\end{array}$ \\
\hline & $\%$ & $\%$ & $\%$ & $\%$ & & P-Value & Estimate \\
\hline \multicolumn{8}{|l|}{ Prior self-help } \\
\hline Family support & 40.0 & 18.0 & 34.0 & 24.0 & 0.45 & 0.13 & 0.47 \\
\hline Friends and colleagues & 46.0 & 14.0 & 28.0 & 32.0 & 0.30 & 0.62 & 0.24 \\
\hline Prayer and/or temple visit & 52.0 & 16.0 & 40.0 & 28.0 & 0.31 & 0.16 & 0.21 \\
\hline None & 46.0 & 8.0 & 26.0 & 28.0 & 0.17 & 0.82 & 0.04 \\
\hline \multicolumn{8}{|l|}{ Prior outside help } \\
\hline Government clinic or hospital & 14.0 & 8.0 & 12.0 & 10.0 & 0.57 & 0.56 & 0.69 \\
\hline Private general physician & 54.0 & 18.0 & 40.0 & 32.0 & 0.33 & 0.35 & 0.22 \\
\hline Faith healer & 20.0 & 4.0 & 10.0 & 14.0 & 0.20 & 0.48 & 0.25 \\
\hline Healing temple & 24.0 & 6.0 & 16.0 & 14.0 & 0.25 & 0.74 & 0.29 \\
\hline Priest or maulvi & 8.0 & 2.0 & 4.0 & 6.0 & 0.25 & 0.56 & 0.37 \\
\hline Other & 12.0 & 2.0 & 10.0 & 4.0 & 0.17 & 0.18 & 0.24 \\
\hline None & 54.0 & 26.0 & 32.0 & 48.0 & 0.48 & 0.03 & 0.43 \\
\hline \multicolumn{8}{|l|}{ More help desirable } \\
\hline General, nonspecific & 70.0 & 40.0 & 60.0 & 50.0 & 0.57 & 0.20 & 0.40 \\
\hline From family & 54.0 & 16.0 & 36.0 & 34.0 & 0.30 & 0.82 & 0.17 \\
\hline From others & 22.0 & 10.0 & 16.0 & 16.0 & 0.45 & 1.00 & 0.55 \\
\hline
\end{tabular}

Only categories reported by more than $5 \%$ ( $\geq 3$ respondents) in at least one series are listed. Agreement refers to identification by both respondents. P-value of McNemar test indicates series-level agreement and estimate of kappa statistic indicates case-level agreement. 